\title{
ASPECTOS RETÓRICOS EN EL AUTO SACRAMENTAL DE EL TESORO ESCONDIDO DE CALDERÓN
}

\author{
A. Robert Lauer \\ Department of Modern Languages, Literatures, and Linguistics \\ 780 Van Vleet Oval, Kaufman Hall, Room 206 \\ The University of Oklahoma \\ 73019-2032 Norman. Oklahoma. USA \\ arlauer@ou.edu
}

[Anuario calderoniano (ISSN: 1888-8046), 5, 2012, pp. 197-214]

Una obra tardía calderoniana como el auto sacramental El tesoro escondido (1679) reflejaría el punto culminante del estilo retórico de Pedro Calderón de la Barca. En forma general y limitada, John V. Bryans, autor de Calderón de la Barca: Imagery, Rhetoric and Drama, estudió algunos de los recursos retóricos en Calderón en $1977^{1}$. No obstante, un estudio completo de las figuras retóricas usadas por Calderón, aun limitándose a solo un auto, requeriría más de un libro. En este ensayo se hace hincapié en las estrategias retóricas más sobresalientes de este auto, con especial énfasis en las siguientes (en forma alfabéti-

${ }^{1}$ Bryans, 1977. 
ca): la acumulación, el epíteto, la etimología, la exclamación, la interrogación, la metáfora y el paralelismo.

La figura retórica más abundante (después del epíteto) en El tesoro escondido es la acumulación ${ }^{2}$. La acumulación puede abarcar la congeries o el sinatroísmo, como indican Lausberg y Mayoral ${ }^{3}$. También puede consistir de una sucesión de más de tres palabras dentro de un período, en cuyo caso se denomina colon o membrum; o de tres o menos, en cuyo caso se llama incisum o articulus ${ }^{4}$. Esta figura de pensamiento se usa para mover el objeto del discurso de una manera rápida y frecuente. En El tesoro escondido, la acumulación aparece 62 veces en series nominales, adjetivales y verbales de diferente extensión. Las series binarias son las de mayor extensión (40 ocurrencias o el 65 por cien del total). Estas son seguidas por las series ternarias (10 muestras o el 16 por cien del total), estas por las cuaternarias (9 ejemplos o el 15 por cien del total) y estas por las quíntuples ( 3 casos o el 4 por cien). A continuación se muestran algunos ejemplos, eliminándose las series semejantes o repetidas ${ }^{5}$. Series binarias: v. 506: «la deuda y la esclavitud»; v. 514: «en sombras y bosquejos»; v. 532: «vida y dulzura»; v. 572: «ver y oír»; v. 580: «sombras y figuras»; v. 698: «dices y haces»; v. 820: «divina y humana»; v. 964: «coronada y adorada»; v. 989: «desierta y desmantelada»; v. 1038: «a logro y ganancia»; v. 1193: «fundidos y deshechos»; v. 1216: «sin plata ni oro»; v. 1222: «sus victorias y tus ruinas»; v. 1227: «ni envidioso ni sangriento»; v. 1238: «oro y plata»; v. 1244: «Baco y Ceres»; v. 1268: «tarde o nunca»; v. 1269: «siempre y presto»; v. 1293: «hijo y padre»; v. 1311: «apurando e inquiriendo»; v. 1330: «partos del sol y la luna»; v. 1652: «confusas y veloces»; v. 1655: «susto y alegría»; v. 1716: «blancas y negras»; v. 1930: «aguarda, espera»; v. 1946: «disfrazada y encubierta»; v. 2112: «Natural y Escrita»; v.

${ }^{2}$ Se usa este término en el sentido amplio que le otorga Lausberg, 1975, p. 145: «La acumulación [...] consiste en la adiectio de miembros oracionales que no están indicados como repetición [...] de miembros oracionales ya puestos». Lausberg clasifica esta figura como una de pensamiento (p. 145).

${ }^{3}$ Lausberg, 1975, p. 145: «La acumulación coordinante [...] se llama plurium rerum congeries». Otrosí, Mayoral, 1994, p. 260, equipara la acumulación con el sinatroísmo o la congeries.

${ }^{4}$ Lausberg, 1975, pp. 224-225 (sección 453).

${ }^{5}$ Ver P. Calderón de la Barca, El tesoro escondido, ed. A. R. Lauer, Pamplona / Kassel, Universidad de Navarra / Reichenberger, en prensa. Se cita por verso. 
2112: "patrïarcas y profetas»; v. 2121: «Carne y Sangre»; v. 2156: «Pan y Vino»; v. 2184: "clara y cierta»; y v. 2212: «nubes y cielos». Series ternarias: vv. 391-392: «admiras, / extrañas y dificultas»; v. 410: «el beleño, el opio y la cicuta»; vv. 466-467: "con majestad, / con pompa y autoridad»; v. 715: «de arado, escoda ni azada»; vv. 982-983: «temerosa, / oscura y enmarañada»; vv. 1506-1507: «los rayos, / los relámpagos y truenos»; v. 1579: «ingrato, obstinado y ciego»; v. 1887: «Saba, Tarsis y Arabia»; vv. 1889-1890: «el oro, / plantas y aromas»; y v. 2109: «sombras, figuras y visos». Series cuaternarias: v. 36: «o rasgo, o viso, o símbolo o figura»; v. 124: «oye, aguarda, espera, escucha»; vv. 126-127: «¿Qué furia / qué horror, qué pasmo, qué asombro?»; vv. 393-394: «te revele, / te informe, advierta e infunda»; v. 805: «las vides, las mieses, las fuentes, las flores»; vv. 883-884: «de nieblas, / granizos, hielos y escarchas»; v. 895: «plantas, flores, vides, mieses»; y vv. 1228-1229: «aromas, / gomas, bálsamos e inciensos». Series quíntuples: vv. 136-138: "¿Qué ansia, qué angustia, / [...] qué delirio, / que frenesí, o qué locura?»; vv. 502-504: "por Adán / [...] a David y a Abrahán, / Jacob e Isaac»; y vv. 2044-2045: «turbada, suspensa, / absorta, ciega y confusa». Como se podrá ver, la acumulación, aparte de identificar listas de objetos o personas de determinada extensión («Pan y Vino»; «Arabia, Tarsis, Saba»; "Adán, David, Abrahán, Jacob e Isaac»), sirve, en el caso de extensiones binarias, para crear contrastes o reiteraciones; en el de las ternarias para manifestar énfasis; en las cuaternarias para mostrar excitación y en las quíntuples para expresar efusión. Las locuciones binarias serían, por lo tanto, elegantes; las ternarias sublimes, las cuaternarias exuberantes, las quíntuples conmovedoras. La oración periódica, por supuesto, sería meramente informativa o progresiva.

Definitivamente el epíteto, como figura tropológica, es el recurso retórico más sobresaliente de El tesoro escondido ${ }^{6}$. Un examen sucinto

${ }^{6}$ El epíteto es un tipo de pronominatio (por lo tanto, un tropo) similar a la antonomasia (ver la retórica atribuida a Cicerón, Ad Herennium, 4, 31, 42, p. 334). Para Lausberg, 1975, pp. 107-109, la antonomasia es un tipo de pronominatio que el insigne retórico alemán considera una variante de la perífrasis y la sinécdoque (o sea, tropos). No obstante, Azaustre y Casas, 1997, pp. 116-117, clasifican el epíteto como «figura de acumulación» y, por lo tanto, una figura de dicción. Sobejano, 1956, p. 15, define este término (el epíteto) en una forma suficientemente amplia para el propósito de este estudio: «El vocablo significaba la palabra o palabras que se añaden a un nombre formando grupo con él, para calificarle de alguna manera». 
de la obra ha identificado 174 ejemplos (varios de ellos de términos repetidos a lo largo de la obra como Humana Naturaleza [término también registrado, aunque menos frecuentemente, como Naturaleza Humana]), de los cuales 27 son dobles o inscritos con un calificativo adicional posnominal. Estos son los ejemplos más sobresalientes, exceptuándose las repeticiones de términos idénticos, de epítetos sencillos: abisinio idioma, indiana región, misteriosa lectura, literal sentido, precioso tesoro, Virgen Tierra, ajenas profecías, propietarias conjeturas, inescrutables misterios, cándida lluvia, aceradas puntas, humanas gentes, neutral sabor, docta lucha, dura lid, nueva deidad, gran tesoro, feliz dueño, suma riqueza, transparente urna, pequeña tumba, soñado tesoro, nueva estrella, mágica ciencia, siria frase, lineadas arrugas, aparente hermosura, despiertos sentidos, lóbrego seno, estrecha cárcel, funesta gruta, duras entrañas, Escondido Tesoro, fantásticas figuras, sacra autoridad, docta Sinagoga, fiel oráculo, gran Mesías, inmenso poder, retórica energía, franca Escala, nueva luz, humanos ojos, crüel instancia, pavoroso centro, divino culto, ciego encanto, nuevo espíritu, Humana Naturaleza, florida tierra, interior decoro, prevista mañana, torcida senda, buen tiempo, verde esmeralda, sencillos pastores, dorados reflejos, vaga región, unido maridaje, errado pie, vírgenes rosas, rudos pastores, festivo coro, Virgen Tierra, Misteriosa Tierra, absoluto dueño, soberana deidad, apagada antorcha, constante amor, infinito tesoro, ventajoso precio, heroico empleo, sacro ceño, etíope Nilo, preciosos leños, ocultos secretos, feliz Arabia, indiano imperio, claros prólogos, felice nacimiento, cambiantes reflejos, ardiente elemento, coronados reinos, contrarios efectos, caudaloso premio, vehemente aprehensión, intempestivo aborto, concebido delirio, bello astro, relativo misterio, nuevo astro, nuevo Lucero, vaga impresión, preñada nube, abortivo concepto, caudatos cometas, erizados cabellos, lejanas noticias, mortales encuentros, mágicos portentos, métrica armonía, líricos amores, aladas tropas, dulces corrientes, docto Hebraísmo, hermosa Sinagoga, rudos pastores, florida patria, nueva gente, cortesano agasajo, enmarañada espesura, generoso pasajero, orientales magos, ricos reinos, curiosa esperanza, supremas majestades, excelsa fábrica, bella serrana, mágicas ciencias, bella Sinagoga, azul esfera, humildes pastores, vírgenes flores, soberana hermosura, peregrina belleza, infinitas riquezas, Cándida Oblea, poderoso rey, precioso incienso, blanda hoguera y buena estrella. Como se puede ver, la mayoría de los epítetos sencillos tienen una función expresiva. Son por lo tanto ejemplos de epithetum ornans. Pocos son redundantes (epithetum constans): verde esmeralda, etíope Nilo (el Nilo nace en el Monte de la Luna en Etiopía, según Tolomeo), Feliz Arabia (el 
epíteto es parte del nombre del país Arabia Felix [las otras regiones serían Arabia Petrae y Arabia Deserta]), coronados reinos y Cándida Oblea.

El epíteto en Calderón, sin embargo, puede manifestarse en varias formas adicionales en El tesoro escondido. Por ejemplo, puede aparecer en su posición normal pre-nominal en forma dupla (dos epítetos), en forma superlativa (sencilla o absoluta), en forma fraseológica (preposicional), en forma agregada y calificativa y en forma agregada y calificativa dupla. En la primera muestra, el valor expresivo del sintagma nominal sería óptimo; en el segundo, soberbio; en el tercero, insólito, en el cuarto, espléndido, en el quinto, exuberante. Ejemplos de estos casos siguen: 1) Sintagma de epíteto duplo: fija y errante estrella (v. 109), humanas, divinas letras (v. 217), supremo gran Júpiter (vv. 1197-1198), nueva celeste imagen (vv. 1666-1667), hermoso, fértil campo (v. 1755); 2) Sintagma de epíteto superlativo: Doctísima Idolatría (v. 141), fertilísimo terreno (v. 1285), más bello astro (vv. 1421-1422); 3) Sintagma de epíteto fraseológico o preposicional: de Balam la Estrella (v. 584), de Jacob la Estrella (v. 585); 4) Sintagma agregado-calificativo (epíteto, sustantivo y adjetivo): débiles varas secas (v. 171), Virgen Tierra pura (v. 250), fértil patria nuestra (v. 269), siria frase suya (v. 376), docta Sinagoga bella (v. 438), torpes deidades falsas (v. 850), mago profeta agorero (v. 1537), pardas sombras densas (v. 1686), raras gentes extranjeras (v. 1712), gallardo extranjero joven (v. 1865); 5) Sintagma agregado-calificativo duplo (epíteto, sustantivo y dos calificativos): yerma alquería, desierta y desmantelada (vv. 988-989).

Un epíteto especial, la antonomasia, se manifiesta en esta obra en relación a asuntos teológicos. Consistentemente, el término escritura (vv. 32, 1930, 1975, 2073, 2127, 2144 y 2149) se refiere al Antiguo Testamento hebreo.Virgen Tierra (vv. 74, 250, 945, 946 y 1002) es la Virgen María. El Escondido Tesoro (vv. 249, 425-26, 455, 460, 463464, 472, 501, 516, 538-539, 577-578, 1408, 1412, 1452, 2055, 20692070, 2103 y 2105-2108) o el Zagal (v. 2101) es Cristo. Baco y Ceres (v. 1244), así como vid y espiga (vv. 482, 484) y vides y mieses (vv. $805,1641)$, por antonomasia en este auto se refieren al pan y al vino de la Eucaristía.

De menor importancia cuantitativa sería la figura de etimología (veriloquium), usada en argumentos respecto al significado de ciertas 
palabras, como indica Cicerón en Topica ${ }^{7}$. Aparecen dos casos en El tesoro escondido: v. 1759: «Belén, que es “casa de pan”" y vv. 2078-2083: «Detrás de esos velos, llega / a manifestarle tú, / será Epifanía tu Fiesta, / que es "ser manifestación", / mostrando en la frase hebrea / que viene a ti en heredad». Las etimologías, obviamente, dan validez culta a cualquier argumento. Para ser eficaces, se deben usar infrecuentemente, como en este caso.

Otro abundante recurso retórico en este auto es la exclamación ${ }^{8}$. Esta figura de dicción se usa en mandatos, invocaciones y expresiones emotivas (de dicha, sorpresa, temor, vehemencia, frustración e incertidumbre). Se identifican en este estudio 34 muestras de esta figura. La exclamación en esta obra sirve principalmente para expresar emociones positivas como la alegría, la dicha o la sorpresa placentera, como se ve en los siguientes once casos: vv. 926-928: «VILLANA 1: ¡Qué bien en ellos se esmaltan / en unido maridaje / trenzas de oro y lazos de ámbar!»; v. 1414: «ARABIA: ¡Dioses, qué segundo sol!» y v. 1415: «TARSIS: ¡Qué segunda aurora, cielos!»; v. 1416: «SABA: ¡Hados, qué segundo día!»; v. 1613: «Sinagoga: ¡Docto Hebraísmo!»; v. 1614: «Hebraísmo: ¡Hermosa Sinagoga!»; v. 1654: «Unos y Otros: ¡Qué contento! ¡Qué

${ }^{7}$ Ver Cicerón, Topica, 8, 35, p. 408. Como Cicerón indica en esta obra, la palabra etimología, que Aristóteles llama symbolon, es lo que en latín se llama veriloquium, aunque Cicerón prefiere el término más común de notatio, ya que para él las palabras son señales de las cosas ("quia sunt verba rerum notae»). Es por lo tanto una figura traslaticia, no disimilar de una metáfora (figura tropológica). Otrosí, en De partitione oratoria, 2, 7, p. 314, Cicerón asocia el término etimología (notatio verbi) con argumentos internos que derivan de los hechos en sí y que se valen de definiciones, enumeraciones y, a la vez, etimologías. Por lo tanto, la figura etimología (notatio verbi) se asocia aquí con semejanzas, las cuales son simplemente 'giros' o 'vueltas' que se dan a las palabras. Los tropi son precisamente eso. Consta notar que para Quintiliano, Institutio oratoria, 9, 1, 9, vol. 3, p. 352, los tropos y las figuras generalmente se combinan en la expresión de un mismo pensamiento: «llud tamen notandum, coire frequenter in eadem sententia et tropon et figuram. Tam enim translatis verbis quam propriis figuratur oratio». Lausberg, 1975, asocia la figura etymologica con la derivatio (p. 138, sección 281) y la definición (finitio), la cual, según él, es un status que «hay que generalizarlo a figura» (p. 186, sección 379). Entre las definiciones «más alienantes», Lausberg menciona las alegóricas (o sea, las tropológicas).

${ }^{8}$ Las figuras de exclamatio y, más adelante, interrogatio, son figuras de dicción mencionadas en la retórica atribuida a Cicerón, Ad Herennium, 4, 14, 22, pp. 282-284. Para Lausberg, 1975, pp. 222-223 (sección 444), son figuras «afectivamente ascendentes», como la apostrophe. 
dicha!»; v. 1669: «SinaGOGA: ¡Qué hermoso rasgo de luces!»; v. 1839: «Gentilismo: ¡Cielos!»; v. 2097: «Gentilismo: ¡Qué soberana hermosura!» y v. 2098: «Los Reyes MAgos: ¡Qué peregrina belleza!». En un segundo nivel, la exclamación se usa en invocaciones, las cuales van generalmente precedidas de una interjección y seguidas de la persona o entidad invocada. Se muestran aquí diez ejemplos: vv. 407-408: «IDOlatría: ¡Ah del lóbrego seno / del Monte de la Luna!»; v. 411: «IDOlatría: ¡Ah de la estrecha cárcel!»; v. 415: «IDOlatríA: ¡Ah del Abismo!»; v. 564: «IDOLATRÍA: ¡Ah del pavoroso centro!»; vv. 1052-1053: «Gentilismo: ¡O, tú, soberana / Inspiración que me animas!»; v. 1272: "Gentilismo: ¡Ah de la feliz Arabia»; v. 1284: «Gentilismo: ¡Ah de las Islas de Tarsis!»; v. 1297: "Gentilismo: ¡Ah de Saba!»; v. 1679: «Hebraísmo: ¡Ay, Sinagoga!»; vv. 2815-2816: «Los Reyes Magos: ¡Pastores de Belén!». En tercer orden, la exclamación se utiliza para expresar sentimientos de frustración o tristeza, a veces en apartes y acompañada de efimeras interjecciones, como se observa en los siguientes cuatro ejemplos: v. 534: «IDOLATRÍA: ¡Confusa de oírlos estoy!»; v. 1090: «IDOlatría: ¡ay!»; v. 1625: «SinAGOGa: (jaquí el sentido y el discurso pierdo!)»; vv. 1769-1770: «GENTILISMO: (joh, quién hallara razones / que uno digan y otro entiendan!)». En cuarto lugar, la exclamación sirve para expresar duda e incertidumbre, como se ve en los siguientes tres ejemplos: v. 1041: «GENTILISMO: ¡ay infelice!»; v. 2099: «SINAGOGA: ¿Quién asegura (¡qué ansia!)»; v. 2100: «IDOLATRÍA: ¿Quién certifica (iqué pena!)». En quinto lugar, la exclamación se usa en lamentaciones: vv. 1-5: «GenTILISMO: ¡Oh, nunca el natural instinto hubiera / [...] / intentado, por esa azul esfera, / seguir al sol en su veloz carrera!»; vv. 6-8: "Gentilismo: ¡Nunca hubiera su genio / intentado antever de su fortuna / el hado en los semblantes de la luna!». En sexto lugar, la exclamación se usa para expresar temor: v. 131: «Gentilismo: ¿Qué miro? ¡Oh, Cielos!»; v. 1650: «Unos y Otros: ¡Qué asombro! ¡Qué temor! ¡Qué espanto!». En séptimo y último lugar, la exclamación se usa en mandatos exaltados o vehementes: vv. 727-728: «NATURALEZA: ¡Que abra sus senos la Tierra / y produzca su Tesoro!»; v. 1500: IDOLATRÍA: « ¡No lo repitáis vosotros!». Obviamente, el uso de la exclamación en una obra de carácter didáctico y teológico, añade, por su carácter emotivo (como en el caso también del 
epíteto), a lo que Viviana Díaz Balsera llama «los inseparables placeres estéticos que brinda el auto"'.

En una obra de carácter teológico y didáctico, no es de sorprender que la interrogación, figura que se presta para la catequesis, sea uno de los recursos estilísticos de dicción más destacados. En efecto, abundan las frases interrogativas determinativas. Un examen conciso de la obra brinda 58 ocurrencias de interrogaciones con /¿qué?/, 25 con /¿cuándo?/, 13 con /¿quién?/, nueve con/¿dónde?/, dos con /¿cuál?/, dos con /¿para qué?/, dos con /¿cúyo?/, una con /¿cuánto?/ y una con /¿por qué?/. A la vez, hay 20 muestras de interrogaciones generales o absolutas. Algunos ejemplos siguen. Las oraciones dubitativas son las más abundantes, con 14 ejemplos de dubitaciones directas y uno, el último, de dubitación indirecta: v. 629: «¿A eso te persuades?»; v. 630: «¿No lo escuchaste tú?»; vv. 661-662: «En fin, ¿resuelves, tirano, / el dejarme?»; vv. 953-954: «¿Abra sus senos la Tierra / y produzca su Tesoro?»; v. 1055-1059: «¿No es tiempo de que me cumplas, / [...] / la prometida palabra / de favorecerme?»; v. 10601061: “¿No es también tiempo que arda / tu apagada antorcha?»; v. 1120: «iTan airada me recibes?»; v. 1221-1225: «ino es fuerza que, viendo / sus victorias y tus ruinas / la envidia, haga que en tu pecho / cebe el etíope Nilo / sus áspides?»; v. 1524: «no nos constan ...?»; v. 1530: «¿Tropas de hombres y caballos ... ?»; v. 1989: «¿y tú?»; vv. 17931794: "¿La que nos anuncia un rey / que ha de dominar la tierra?»; v. 1795: «¿Si es el que esperamos?»; vv. 1936-1937: «[...] ¿Esta / no es nuestra Idolatría?» y v. 1790: «[...] si era o si no era». El texto de $E l$ tesoro escondido también contiene tres interrogaciones indirectas disyuntivas (v. 144: «o mi interés o mi astucia»; v. 576: «Sepa en qué»; vv. 976-977: «es respeto o es / temor») y dos interrogaciones directas retóricas: vv. 1122-1123: «¿No te dije cómo habías / de hallarme?» y vv. 2000-2001: «¿Dejarme no es harta ofensa, / por buscarle, a mi pesar?». Además de su valor lingüístico, varias de estas interrogaciones tienen otras funciones, retóricas y dramáticas, y, por ende, sirven en

${ }^{9}$ Díaz Balsera, 1997, p. 5. No obstante, no comparto el temor de esta amable colega de que los intereses de la teología hubieran estado en peligro de haber sido desplazados por este deleite (o seducción) estético. Más convincente es la opinión de Arellano, 2000, p. 331: «Los placeres estéticos del auto tampoco tienen por qué oponerse a su función pedagógica, sino que se ponen al servicio de la misma, y cumplen viejas exigencias de la poesía (y los autos son poesía, no se olvide)». 
algunos casos para reiterar y enfatizar afirmaciones previas o para identificar a personajes dramáticos.

Un estudio completo de los tropos en Calderón quedaría fuera del alcance de este estudio. No obstante, se plantea aquí un brevísimo y conciso análisis de la metáfora y otras figuras traslaticias en ocho ejemplos notables de El tesoro escondido. La metáfora en Calderón puede ser aparentemente sencilla, como se ve en los vv. 1365-1367: «Dejadme a mí hablar primero, / que las canas siempre tienen / ganado ese privilegio». Aquí «las canas» funcionarían como un tipo de pars pro toto para referirse al Rey de Arabia. Sin embargo, la sinécdoque ${ }^{10}$ de "las canas» funciona dentro de un complejo sistema de relaciones en el cual se asocia la edad, y con ella la dignidad estamental, por un lado; por otro, el color blanco o plateado, que en Calderón puede asociarse con una cualidad menor en comparación con el amarillo y dorado, y por lo tanto, con la caducidad. Estas asociaciones son importantes en un nivel semántico, ya que Arabia, como uno de los representantes del Gentilismo, será uno de los actantes desplazados por la inminente ley de gracia y un rey joven mesiánico.

Otras metáforas aparentemente sencillas pero no exentas de complejidad aparecen en los vv. 986-987 y 1594-1595. En el primer ejemplo, la Naturaleza, al ver que oscurece, indica que «la negra tez de la noche / se afeita de nieve blanca». Se indica así la aparición de las estrellas en el firmamento. La referencia a «se afeita» ('se adorna'), sugiere una acción artística (en un auto en que abundan referencias pictóricas asociadas con la fe), así como el momento histórico del auto (invierno) y el gran evento que está a punto de ocurrir en Belén (la Natividad). Al anticipar lo que está a punto de ocurrir, este parlamento tiene dramáticamente una función deíctica catafórica (anticipando lo porvenir). El segundo ejemplo es recitado por el Hebraísmo y la Sinagoga: "Sobre noche tan fría, / que platea los campos que el sol dora». Aunque en ambos casos platear y dorar son metáforas de iluminación, a la vez son imágenes metalúrgicas. El aspecto de aleación es

${ }^{10}$ Azaustre y Casas, 1997 , p. 87 , clasifican la sinécdoque como un tropo de contigüidad o inclusión; asimismo, observan que frecuentemente «la sinécdoque es incluida en la metonimia». Cicerón, De oratore, 3, 43, 169, p. 134, sugiere, en efecto, que las palabras usadas en forma metonímica (y no en forma literal) son un tipo de metáfora: «sunt translata quodam modo» $(3,43,169)$. 
importante en un auto que desde su principio hasta su final hace referencias astrológicas y, a la vez, fabriles (por la asociación de los astros con ciertos metales: la plata con la luna; el oro con el sol). Asimismo, estas imágenes se relacionan con el aspecto monetario que está a punto de ocurrir: la venta de Belén y su Tesoro al Gentilismo por parte de la Sinagoga y el Hebraísmo (es inevitable recordar asimismo las treinta monedas de plata [Mateo, 26, 15]). Lo aparentemente sencillo, por lo tanto, no excluye lo complicado.

Obviamente, algunas metáforas en Calderón son más complejas, como se puede ver en los vv. 54 y 1278. En el primero, Gentilismo llama al sueño aparentemente provocado por la voz no entendida de la Música "paréntesis [...] de mi vida». En el segundo, el Gentilismo llama los primeros rayos de luz del sol «claros prólogos del día». Tanto paréntesis como prólogos son metáforas gramaticales. En el primer caso, paréntesis significaría suspensión de los sentidos; en el segundo, inicios. Ambos referentes son curiosos e innovadores. A la vez, reflejan específicamente el tiempo y el lugar de su producción, la España del siglo XVII, así como sus preferencias culturales por este tipo de figura que proviene de la Antigüedad y la Edad Media, como indica Ernst Robert Curtius ${ }^{11}$. Estas metáforas forman por lo tanto un registro de su época, por un lado; por el otro, un enlace con una tradición cultural latina que perdura en la edad moderna del Barroco español.

Otras recónditas metáforas calderonianas tienen que ver con lo embriológico en combinación con lo cosmológico y lo alquímico. En el v. 1330 , el Gentilismo llama al oro y la plata que se producen en los montes de Arabia "partos del sol y la luna». O sea, los montes son como cuerpos que producen o dan a luz preciosos metales. A la vez, por ser el oro y la plata metales asociados cosmológica y alquímicamente con el sol y la luna, tendrían que ser prole de estos planetas. Otrosí, en los vv. 1390-1396, al explicarles el Gentilismo a los Reyes Magos que desea comprar el tesoro escondido que supuestamente se encuentra en Belén, ellos se resisten:

ARABIA Esa es vehemente aprehensión, hija de tu devaneo

11 Curtius, 1963, pp. 414-416. 


$\begin{array}{ll}\text { SABA } & \begin{array}{l}\text { Es intempestivo aborto } \\ \text { de los fantasmas del sueño }\end{array} \\ \text { TARSIS } & \begin{array}{l}\text { Es concebido delirio, } \\ \text { embrión del pensamiento. }\end{array} \\ \text { GENT } & \text { No es sino iluminación. }\end{array}$

(vv. 1390-1396)

El proceso metafórico empieza al llamar Arabia hija a la aprehensión del Gentilismo. Saba continúa la alegoría al llamar aborto a la hija (o sea, a la idea mal pensada o concebida). Tarsis continúa la alegoría llamando a este aborto un delirio concebido (de concepción) y un embrión (feto, origen) del pensamiento. El propio Gentilismo remata la alegoría llamando a su idea iluminación (de alumbrar o dar a luz). Finalmente, la asociación entre lo embriológico y lo cosmológico se ve claramente en los vv. 1506-1515, donde la Idolatría, ignorando la presencia de la nueva estrella de Belén, habla de otros signos similares (abortivos conceptos) que nacen de preñada nube, cuyas exhalaciones (meteoros) son hijas de dos elementos (el fuego y el aire).

Finalmente, se encuentran en este auto metáforas o conceptos alegóricos de gran complejidad y exuberancia. En los vv. 260-269, el Gentilismo le dice a la Idolatría que recorrerá la tierra en busca de un tesoro escondido:

$$
\begin{aligned}
& \text { Y así, a costa de tu ausencia } \\
& \text { he de correr en su busca } \\
& \text { el Orbe, si sé vagar } \\
& \text { desde esta primera cuna } \\
& \text { del Sol, fértil patria nuestra, } \\
& \text { donde entre flores madruga, } \\
& \text { hasta donde entre cristales } \\
& \text { yace en transparente urna, } \\
& \text { de cuyo Panteón aun todo } \\
& \text { el Mar es pequeña tumba. }
\end{aligned}
$$

O sea, el Gentilismo viajará de oriente (la primera cuna del Sol) a occidente (donde «muere»y "se sepulta» el sol). La metáfora, por lo tanto, es de gestación y geriatría, con claros recuerdos del tópico de la cuna y la sepultura que se encuentra en Calderón, Quevedo y otros 
poetas conceptistas y cultos del Barroco español. Pero Calderón va más allá. El occidente aquí es el fin de la tierra, de las Hespérides, donde solo hay mar (cristales). Al hundirse el sol en el mar, éste se convierte en transparente urna (por su elemento líquido) donde será colocado el cuerpo difunto del sol. A la vez, por ser el sol el mayor planeta, la inmensidad del mar será una pequeña tumba. Se llega así a la alegoría, a la hipérbole, a la fastuosidad.

La metáfora en Calderón, por lo tanto, forma parte de un complejo grupo de asociaciones analógicas, culturales y lingüísticas que abarcan la totalidad de la experiencia humana, desde lo particular y nimio (canas) hasta lo soberano e ilimitado (el orbe).

Después del epíteto (y la congeries) la figura llamada isocolon (compar) ocuparía, con la interrogación, el cuarto lugar en número de manifestaciones en este auto ${ }^{12}$. Esta figura de dicción, que podría llamarse simplemente paralelismo (de frases, cláusulas y oraciones), se usa para mover el objeto del discurso de una manera lenta e infrecuente. Sin embargo, en Calderón, este recurso aparece 58 veces en varias extensiones. La más común es la extensión binaria (47 ejemplos). Hay, sin embargo, siete paralelismos de extensión ternaria, dos de extensión cuaternaria, uno de extensión quíntuple y uno de extensión múltiple (de once elementos). A continuación se muestran cinco ejemplos (uno de cada extensión).

Un decidido ejemplo de un paralelismo binario se ve en el soliloquio en silvas de la Idolatría en los vv. 1079-1082:

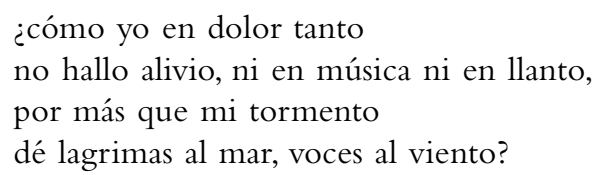

(vv. 1079-1082)

Un contundente ejemplo de un paralelismo ternario se ve en las locuciones jaculatorias en romance de los Reyes Magos en los vv. 1414-1419:

12 La retórica atribuida a Cicerón, Ad Herennium, 4, 19, 26, p. 294, no distingue claramente entre la figura llamada membrum $(4,19,26$, p. 294) y la denominada compar o isocolon $(4,20,27$, p. 298). No obstante, ambas figuras son ejemplos de paralelismos de varias extensiones en frases, cláusulas y oraciones. 
$\begin{array}{ll}\text { Arabia } & \text { ¡Dioses, qué segundo sol! } \\ \text { TARSIS } & \text { ¡Qué segunda aurora, cielos! } \\ \text { SABA } & \text { ¡Hados, qué segundo día! } \\ \text { ARABIA } & \text { Me deja a sus rayos ciego. } \\ \text { TARSIS } & \text { A mí a su luz deslumbrado. } \\ \text { SABA } & \text { A mí a su esplendor suspenso. }\end{array}$

(vv. 1414-1419)

Un elocuente ejemplo de un paralelismo cuaternario se observa en la respuesta en redondillas de la Sinagoga al Hebraísmo en los vv. 517-532:

¿Qué es ver una Zarza, ufana de ser llama y no ser ruina, sino unión de una Divina Naturaleza y humana? ¿Qué es ver de una Escala el vuelo, que al Cielo la Tierra iguala, sino dar en franca Escala comercio entre Tierra y Cielo? ¿Qué es ver de veneno lleno el áspid, que al hombre mata, sino que el que le trata sea su contraveneno?

¿Qué es ver que una nube pura llueva el rocío cuajado, sino que en solo un bocado dé el Cielo vida y dulzura?

(vv. 517-532)

Un categórico ejemplo de un paralelismo quíntuple se manifiesta en el conjuro en romance de la Idolatría en los vv. 379-391:

Y siendo así que, en el fuego,

- cuando a los dioses consulta

el imperio de mi voz-,

la piromancia ejecuta;

la heteromancia en el aire;

la hidromancia en la espuma

del mar; la nigromancia, 
de la tierra, en sepulturas de cadáveres, que yertos responden a mis preguntas; $\mathrm{y}$ en fin, la quiromancia en las lineadas arrugas de la mano $[\ldots]$.

(vv. 379-391)

Finalmente, un exuberante ejemplo de un paralelismo múltiple (de once elementos) se percibe en la respuesta en romance de la Idolatría al Gentilismo en los vv. 315-328:

Pues cuando más desvelada
de ellas valerse procura,
halla ojos que no ven,
halla oídos que no escuchan,
memoria que no se acuerda,
entendimiento que duda,
voluntad que no apetece,
apetito que no gusta,
tacto que no siente, olfato
que no distingue y, en suma,
sobre arbitrio que no elige
y lengua que no pronuncia,
corazón que solo muestra
lo que vive en lo que pulsa.

(vv. 315-328)

Como se puede ver, la figura de compar añade musicalidad al discurso al crear un cierto ritmo que después se repetirá. Otrosí, las repeticiones paralelas hacen inevitable el uso de otras figuras retóricas como la anáfora y la similicadencia. Estas tácticas retóricas crean un tono altamente emotivo, por un lado, y por otro, ejercen un poder agudamente suasorio. No es accidental que la figura de compar se use en extensas listas que proveen e inculcan información que, expresada en forma más sencilla, acaso no sería eficaz o felizmente captada. Así se nos suministra aclaración, por ejemplo, sobre los cinco sentidos externos (vista, oído, olfato, gusto y tacto), los cinco sentidos internos 
(sentido común, memoria, imaginación, instinto y raciocinio), las tres potencias del alma y las múltiples artes divinatorias, amén de otras. El paralelismo es la figura retórica de la instrucción, la persuasión, la reiteración, el encanto, la seducción y, en último caso, la redención ${ }^{13}$.

Como epílogo a esta sección, se podría hablar de la perfecta combinación de acumulación y paralelismos en la figura de pensamiento que la retórica atribuida a Cicerón, Ad Herennium, denomina frequentatio o acumulación ${ }^{14}$. El filólogo alemán Ernst Robert Curtius denominó a este proceso «summation schema» ${ }^{15}$. Con más precisión, los críticos y poetas españoles Dámaso Alonso y Carlos Bousoño designaron este sumario como proceso "diseminativo-recolectivo» ${ }^{16}$. Esta figura primero disgrega una serie generalmente nominal en estructuras paralelas y después la resume, frecuentemente, aunque no siempre, en el mismo orden de la diseminación. Por su reiteración, éste es un recurso hondamente impresionante y persuasivo. En El tesoro escondido se manifiestan dos casos de frequentatio: en los vv. 481-484 y 805-815. El primero, más corto, simplemente reitera referentes teológicos significativos para su mayor comprensión alegórica:

León y cordero hay quien diga

Que es vid y espiga; y no infiero

yo por eso que es cordero, ni león, ni vid, ni espiga.

(vv. 481-484)

El segundo, más extenso y desarrollado, enumera primero y después elabora cada referente:

Música A la reina del Pueblo escogido, deidad soberana, que de la ley tesorera domina

13 En este respecto estoy de acuerdo con Dietz, 1982, p. 76, quien opina que la popularidad del auto sacramental en España se debe más a su aspecto educativo que al de defensa de la fe.

14 Cicerón (autor atribuido), Ad Herennium, 4, 40, 52, p. 360. Para un estudio de esta figura en Cervantes, ver Lauer, 2005. Respecto a Calderón (y Zabaleta), ver Lauer, 2011.

15 Curtius, 1963, p. 289.

16 Alonso y Bousoño, 1970, p. 58. Ver también Alonso, 1971, p. 438. 


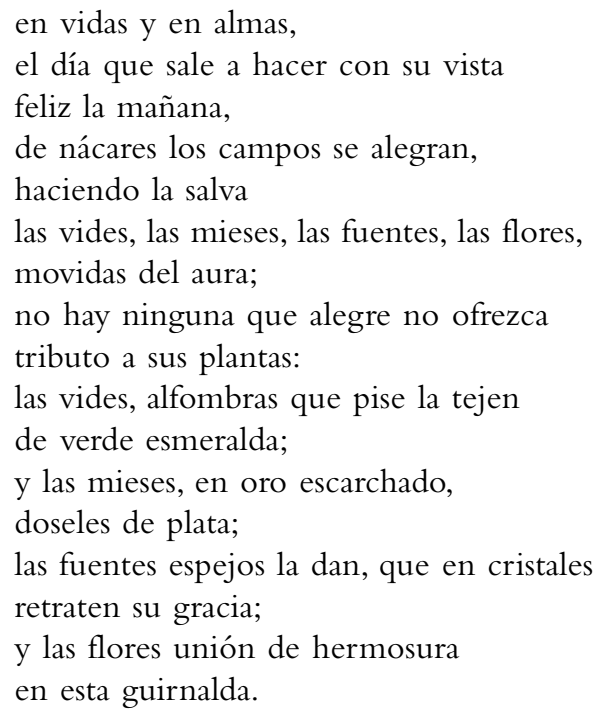

(vv. 805-815)

Obviamente, por su aspecto de amplificación, la figura de frecuentación se presta para encomios, como en este caso. Forma así parte de la retórica epideíctica.

La riqueza de los recursos retóricos calderonianos está todavía por estudiarse a fondo en todas sus dimensiones. Se espera que este breve estudio sobre algunas figuras retóricas manifestadas en este auto sea de alguna utilidad para apreciar o entender de forma óptima su complejo y eficaz sistema oratórico. 


\section{Bibliografía}

Alonso, D. y C. Bousoño, Seis calas en la expresión literaria española, Madrid, Gredos, 1970.

Alonso, D., Poesía española. Ensayo de métodos y límites estilísticos, Madrid, Gredos, 1971.

Arellano, I., "Los estudios sobre los autos sacramentales de Calderón», en Estado actual de los estudios calderonianos, ed. L. García Lorenzo, Kassel, Reichenberger, 2000, pp. 325-349.

Azaustre, A. y J. Casas, Manual de retórica española, Barcelona, Ariel, 1997. Bryans, J.V., Calderón de la Barca: Imagery, Rhetoric and Drama, London, Tamesis Books, 1977.

Calderón de la Barca, P., El tesoro escondido, ed. A. R. Lauer, Pamplona / Kassel, Universidad de Navarra / Reichenberger, en prensa.

Cicero (Cicerón), Ad Herennium, trad. H. Caplan, vol. 1, Loeb Classical Library 403, London / Cambridge, William Heinemann / Harvard University Press, 1968.

- De oratore Book III, en De oratore Book III, De fato, Paradoxa stoicorum, De partitione oratoria, trad. H. Rackham, vol. 4, Loeb Classical Library 349, Cambridge / London, Harvard University Press / William Heinemann, 1982, pp. 1-185.

- De partitione oratoria, en De oratore Book III, De fato, Paradoxa stoicorum, De partitione oratoria, trad. H. Rackham, vol. 4, Loeb Classical Library 349, Cambridge / London, Harvard University Press / William Heinemann, 1982, pp. 305-421.

- Topica, en De inventione, De optimo genere oratorium, Topica, trad. H. M. Hubbell, vol. 2, Loeb Classical Library 386, Cambridge / London, Harvard University Press / William Heinemann, 1976, pp. 375-459.

Curtius, E. R., European Literature and the Latin Middle Ages, trad. W. R. Trask, New York, Harper \& Row, 1963.

Díaz Balsera, V., Calderón y las quimeras de la culpa. Alegoría, seducción y resistencia en cinco autos sacramentales, West Lafayette, Purdue University Press, 1997.

Dietz, D. T., «Liturgical and Allegorical Drama:The Uniqueness of Calderón's Auto Sacramental», en Calderón de la Barca at the Tercentenary: Comparative Views, ed. W. M. Aycock y S. P. Cravens, Lubbock, Texas Tech Press, 1982, pp. 71-88.

LAUER, A. R., "Usos de la figura retórica de frequentatio en el Quijote», en Cervantes y su mundo II, ed. K. Reichenberger y D. Fernández-Morera, Kassel, Reichenberger, 2005, pp. 283-294.

- «La figura retórica de reiteración en Troya abrasada de Juan de Zabaleta y Pedro Calderón de la Barca», en Alarconiana: Primer Coloquio Internacional 
Juan Ruiz de Alarcón. Actas selectas, ed.Y. Campbell y L. C. Salazar, Ciudad Juárez, Universidad Autónoma de Ciudad Juárez, 2011, pp. 185-194.

Lausberg, H., Elementos de retórica literaria, trad. M. Marín Casero, Madrid, Gredos, 1975.

Mayoral, J. A., Figuras retóricas, Madrid, Editorial Síntesis, 1994.

Quintilian (Quintiliano), Institutio oratoria, trad. H. E. Butler, vol. 3, Loeb

Classical Library 126, Cambridge / London, Harvard University Press / William Heinemann, 1986.

Sobejano, G., El epíteto en la lírica española, Madrid, Gredos, 1956. 